JACEK NorkOWSKi OP

\title{
Brain-based Criteria of Human Death. Study of the Issue*
}

\section{Legal Aspects of the Theory of so-called Brain Death}

Until 1968, the legal definition of death, unchallenged by anyone, was used all over the world, and referred to two main symptoms: the cessation of heart functions and breathing. In American law death is defined as "(...) stopping blood circulation, and the associated cessation of vital functions such as breathing, heartbeat, etc." It continues that "Death occurs when life is over and cannot be detected until the heart rate and breath have stopped. Death is not a continuous phenomenon, but takes place at some specific moment."

However, the development of medical technology, including the use of respirators, has led to doubts as to the validity of such a definition of death. It was argued that the patient who has not regained consciousness for a long time despite a heartbeat and continuous (although usually assisted) breathing in reality is no longer alive and doctors' actions only mask this fact. A new legal definition of death, based on more appropriate medical criteria, was therefore proposed.

These conclusions were not without consequences. In 1968, a special committee established at Harvard University (Harvard Ad Hoc Committee) proposed that death of the entire brain should be regarded as a criterion for declaring a person dead. This criterion was first used in legislation in Kansas, USA in 1972. The definition of death adopted there made it possible to pronounce someone dead solely on the basis of a person's brain state. It reads as follows: "A person shall be considered to be dead from a medical and legal point of view if, in the opinion of a medical practitioner, based on recognised standards of medical art, the function of breathing and cardiac action is not established on its

STV 42(2004)2.

Black's Law Dictionary, 1951, 488. 
own, either because of illness or because of factors which have caused, directly or indirectly, the cessation of these operations or because of the time from the cessation of these operations, any resuscitation effort shall be regarded as not giving rise to any hope; in this case death shall take place when these operations cease; or a Person will be considered to be dead from a medical and legal point of view if, in accordance with a medical opinion based on recognised standards of medical art, there is a lack of spontaneous brain function; and if, in accordance with recognised principles of medical art, during attempts to maintain or restore spontaneous circulation and breathing it appears that further attempts at resuscitation or support of bodily functions are unsuccessful, death will occur when these conditions occur for the first time. Death must be declared before any vital organ is removed for transplantation (...)"2.

As we can see, the new legal and medical definition of death is alternative: on the basis of this definition, the doctor can rule on the death of the patient on the basis of both the criteria of previous ones, i.e. cessation of blood circulation and breathing, as well as new ones: cessation of brain functions. In most countries of the world, legislation modelled on that above-cited approach has been adopted. One detail should not escape our attention: the new definition of death refers for the first time to the procurement of organs for transplantation. One may therefore have the impression that this definition was introduced in order to legalise this practice. The authors who supported the efforts to change the law in this direction did not hide the fact that this was what they wanted.

These authors assumed that:

(A) In the event of irreversible cessation of all brain functions, we are dealing with the death of a human being;

(B) The cessation of any brain functions can be clearly demonstrated by appropriate medical tests;

(C) There is a consensus on this issue in the healthcare communities and society as a whole.

Initially, it seemed that this new definition of death would not arouse more serious controversy. This was indeed the case until the 1990s. For some time now, however, opposing voices have started to appear increasingly more often. All three assumptions mentioned above, on which the new definition of death is based, are subject to criticism. Thus, it appears that:

2 A.S. Moraczewski, J.S. Showalter, JD, MFS., Determination of Death. The Theological, Medical and Ethical Issues, St. Louis-Missouri 1982, 12. 
Ad. (A) It is not certain that even a complete cessation of brain functions signifies the death of a human being;

Ad. (B) We cannot confirm the complete and irreversible cessation of all brain functions on the basis of tests which are designed for this purpose; moreover, the vast majority of patients with brain damage meeting the criteria of socalled brain death show signs of action of at least some parts of the brain;

Ad. (C) There is no consensus on the rightness or wrongness of the theory of so-called brain death in many different environments, especially among doctors.

\section{Medical Aspects of the Theory of so-called Brain Death}

It can be noticed that in medical circles the protest against the theory of brain death is strongest ${ }^{3}$. The criteria of cerebral death cannot be defended first of all from the medical point of view. The paradox is that $27 \%$ of those who procure the human heart for transplantation are convinced that they are murdering a still alive human being ${ }^{4}$. Why is that? We must come back to accusation B for a moment.

Many authors criticise the crushing medical criteria of cerebral death. In their opinion, they are superficial, inadequate and in no way does it inform us about the state of the whole brain. During the discussion on this subject even supporters of the theory of brain death admitted this fact ${ }^{5}$. In almost all patients with symptoms of so-called brain death, there are signs of activity of at least some parts of the brain. It includes:

1) The occurrence of cerebral body temperature control exercised by a temperature centre located in the hypothalamus, which is part of the brain;

2) The secretion of hormones by the pituitary gland, which protects the body against uncontrolled urine excretion ${ }^{6}$;

3) Positive EEG results in $20 \%$ of patients who underwent this examination using the classical method ${ }^{7}$ and in a much higher percentage of patients with an intraventricular electrode ${ }^{8}$;

3 M. Potts, P.A. Byrne, R. Nilges, Beyond Brain Death. The Case Against Brain Based Criteria for Human Death, Dodrecht 2001, 1-2.

4 Ibid., 202.

5 Ibid., 150. Evans is quoting Pallis, Harley, ABC of Brain Stem Death, 30.

6 Ibid., 148.

7 Ibid., 164 .

8 Ibid., 197. 
4) Many patients, from whom a heart for transplantation has been procured react to a cut in the form of an accelerated heart rate, increased blood pressure and violent movement of the limbs ${ }^{9}$ (these symptoms are evidence of brainstem function and may indicate the person feels pain);

5) Due to the above described reactions in donors, there is a necessity of undergoing general anaesthesia as for "normal" surgery (routine practice in many ${\text { countries })^{10}}^{10}$

6) The possibility of a significant (even over one year) extension of life of patients diagnosed as dead according to cerebral death criteria, if appropriate drugs are used;

7) The fact that a pregnant woman, after falling into what is known as brain death, was able to give birth to a healthy baby some time later ${ }^{11}$.

All these symptoms are ignored when assessing the health of a patient with a brain injury and, despite their presence, such a patient, after a superficial test, is considered a deceased person under the applicable law. For this reason, for so many doctors who are familiar with the problem, the theory of brain death is pure fiction.

This is the reason why so many doctors have protested in various countries. According to these doctors, the condition of patients classified as deceased due to the occurrence of "brain death" can at most be regarded as close to death (near death syndrome), but certainly not as a condition of death that has already occurred $^{12}$.

In addition, many of these patients respond positively to new types of treatment for brain damage. The use of therapy by lowering the temperature of the brain to $33^{\circ}$, in many cases allows the avoidance of the development of a condition defined as cerebral death in patients with a damaged brain. Therefore, the practice of implementing preparatory procedures for the removal of organs in patients still alive and refusing them appropriate treatment cannot be accepted. It should be remembered that some tests and examinations, e.g. intentional breath-holding or angiography in patients with damaged brains cause their condition to deteriorate and accelerate the onset of symptoms known as

$9 \quad$ Ibid., 188.

10 Ibid., 151.

11 D.A. Shewmon, "Is it reasonable to use as a basis for diagnosis death the U.K. protocol for the clinical diagnosis of 'brain stem death'? Presentation to the Linacre Centre for Health Care Ethics $20^{\text {th }}$ Anniversary International Conferences," "Issues for Catholic Bioethics," Queens' College, Cambridge, July 1997.

12 M. Potts, P.A. Byrne, R. Nilges, op. cit., 197. 
the state of cerebral death. Some critics of the theory of brain death therefore propose the withdrawal of the very concept of brain death and replace it with brain failure, which seems to be a proposal that is justified in all respects ${ }^{13}$. It is therefore impossible to conclude that argument (B) has a sufficiently strong scientific basis.

On the basis of these opinions, it is evident that there is no consensus among doctors themselves on the issue of brain death. Thus, argument (C) of the three mentioned above, on which the justification of so-called brain death is based, is also challenged. We have yet to consider argument (A). This argument is an example of a meeting of medical and philosophical problems with the predominance of the issue on the side of the latter.

\section{Philosophical and Ethical Analysis of the Issue}

Argument (A) is certainly the most interesting from a philosophical point of view. It cannot be unravelled by medical arguments alone, but requires the choice of an anthropological vision. In it we come to the question about the very nature of man. Prof. Seifert, one of the experts on the subject, stresses that the concept of death necessarily depends on the concept of human life, the human individual and the human mind ${ }^{14}$. In this sense, this issue cannot be regarded as the domain of empirical sciences, but as a philosophical issue. So if human life is considered to be the life of the whole human body understood as an integrated whole, then death means the end of physical life (the death of that particular bodily being). However if life is interpreted in terms of higher consciousness, thought, willingness to act, speech, and the suchlike we have to choose between two possibilities:

(1) the ontological background of the human mind as a subject of higher human consciousness is the brain (or part of it),

(2) the mind has the ability to exist on its own and the brain is only a necessary condition for the emergence of human consciousness, but not its main cause.

The proponents of (1) believe that the cerebral cortex is "the seat, source and subject of thought," while those who consider (2) to be the true view claim that the human mind is different from matter and not accessible to matter. In the thinking of the proponents of view (1) Seifert notes an error, which he

13 Ibid., 192.

14 Ibid., 206-207. 
calls actuality. This error consists in identifying the ability to act consciously, that is to say, some attribute and function of the human individual, with the subject of consciousness itself.

Seifert and other authors (e.g. D.A. Jones) also make a precise distinction between medicine as an empirical science and philosophy ${ }^{15}$. They stress the lack of a necessary link between the death of the brain and that of a human being. For such a relationship to be logically necessary, an additional assumption must be made that the existence of the human individual is necessarily linked to the existence of a functioning brain. However, this is a philosophical assumption, not an empirical truth, and as such, on the basis of the natural sciences, it is impossible to prove. In such a case, a doctor's competence is limited to determining the patient's brain condition and possible degree of damage to the organ, and does not entitle one to decide whether this means death or not. Even if the brain were to be completely destroyed, which, as we know, almost never happens in patients classified as deceased due to brain death, the doctor can only competently conclude that such a fact (total destruction of the brain) has taken place. Whether this means the death of a human being is a question beyond the reach of medicine as an empirical science.

Life itself provides us with important arguments for this discussion. Many authors dealing with the issue of brain death quote a shocking fact in their speeches. This is the case of a child who had his whole brain destroyed as a result of a history of meningitis ${ }^{16}$. The child, meeting all the criteria for cerebral death, survived fourteen years in this state. This fact is systematically ignored by proponents of the theory of brain death. It destroys the philosophical basis of this theory, which is based on the conviction that the organ integrating the body as a whole is the brain (or rather the brain stem) and if it can be shown that this organ has been destroyed, then such integration no longer takes place and that the body is dead.

However, some extremely important details should be noted here. The belief that the brain stem must function for the life of the body is an empirical issue, just like any other medical problem, and not an a priori theorem, as is presented by the proponents of the theory of brain death. It is only right to repeat after Jones that it is becoming increasingly apparent that damage, or even death of the whole brain, is not tantamount to death of the body as a whole ${ }^{17}$. Observational data concerning patients with cerebral death confirm

15 Ibid., 101.

16 Ibid., 98.

17 Ibid., 99-100. 
this position. The bodies of these patients are undoubtedly integrated when they control their temperature, blood pressure, circulation, food assimilation processes, urine production and resistance to infections. Also, breathing, understood as a metabolic process, continues (the respirator only replaces the action of the diaphragm). A comprehensive, strong reaction to skin incisions, which even necessitates the use of general anaesthesia during heart procurement for transplantation, is further confirmation of the fact that we are dealing with integrated organisms, i.e. living organisms.

Jones rightly points out that the integration of the body is its work as a functioning whole, not the effect of a single organ, even if it is the brain. Therefore, the death of the body cannot be equated with the death of any single organ, but is the result of the destruction of whole systes, on which the functioning of the body depends. Let us reiterate that the bodies of people with cerebral death symptoms are alive, not dead.

However, can it not be legitimately claimed that the death of a human being must not be tantamount to the death of his body? This dualistic way of thinking is now common. It is said that the body is alive, but the human individual is no longer. This is the Cartesian separation of a person from his or her body, which, however, is not philosophically legitimate. The human individual cannot be identified with his thought or consciousness without falling into logical contradictions. Man discovers his existence and develops his consciousness and has a sense of his identity precisely (though not exclusively) because he has a body. Already the Boeotian definition of the person as an intelligent entity (Persona est rationalis naturae individua substantia) drew attention to the bodily aspect of the person as belonging to its nature. It does not seem possible for this aspect to be omitted in the description of the person. However, this is what all those who, despite the fact that the body of a sick person with a damaged brain being alive, claim that this does not mean the life of a human being, because the sick person will probably not regain consciousness any more.

To sum up, it must be said that in the thinking of various authors a certain characteristic mistake can often be observed, consisting in reducing the human being to his mind, and then to the brain itself (or even only a part of it) identified with thinking and consciousness. In short, the life of the human individual is reduced by them to the life and functioning of the brain. This is also often understood by believers, who place the soul, according to Descartes' thinking, only in the brain and not in the whole human body. However, we know that the philosophical tradition associated with Aristotle and St. Thomas of Aquinas solved the problem of the relationship between body and soul in a different way. According to this tradition, the soul is a form of the body and as such it 
is bound first to the body as a whole and only secondarily to individual parts of the body, including the brain ${ }^{18}$. Thus, man cannot be considered as a mind functioning in a foreign, as it were for him, environment, which is the Cartesian body-machine, but should be understood as a particular being, in which the soul and body enter into a very deep relationship of mutual dependence, in which the soul fulfils the function of a substance form, and the body of matter.

The empirical data given above confirm the truth of this view. The human body does not die when its brain is damaged, if other organs are working properly. The human body can remain alive, even if it has lost consciousness, perhaps forever. If we assume that the death of a human being can precede the death of his body, on which the whole theory of cerebral death is based, then we will have to consider that a person dies twice:

1) when his death is pronounced on the basis of brain death criteria,

2) when his body dies.

After all, it is difficult to deny that the body of every human being, even one who has been found to be in the state of so-called brain death, is still a body of a representative of the homo sapiens species. So what does the death of this body mean in this situation? Can it be called something other than the death of this man? Does this fact not even show the artificiality of the whole concept of so-called brain death, which tries to separate the death of a human being from the death of his body?

The legal acceptance of the theory of brain death has also led to many contradictions and paradoxes. So we have a situation in which a person is alive according to the law of one country and deceased according to the law of another country. This is due to the fact that the criteria for determining brain death, adopted in individual countries, differ considerably ${ }^{19}$. In Japan, however, we deal with an extremely specific situation, since a person in the state of so-called brain death is considered to be alive or dead, depending on the record in his Donor Card (transplant donor card). So if this person agrees to be a donor, he or she is considered dead, and if not, Japanese law treats him or her as a living person ${ }^{20}$. In addition, doctors who are obliged to make decisions about the condition of patients suffering from brain damage are under enormous pressure from

18 Summa Theologiae I, q. 76, art. 8: „(...) Tarnen attendendum est quod, quia anima reąuińt diversitatem in partibus, non eodem modo comparatur ad totum et ad partes: sed ad totum quidem primo et per se, sicut ad proprium et proportionatum perfectibile; ad partes autem per posterius, secundum quod habent ordinem ad totum."

19 M. Potts, P.A. Byrne, R. Nilges, 66.

20 Ibid., 191. 
transplantation teams to classify these patients as deceased. These problems at the legal level confirm the thesis that the theory of brain death inevitably leads to a dead end not only in medicine, but also in law, philosophy and morality.

For how can the concept of brain death be judged from the ethical side? Can it be defended? Supporters of this concept can be divided into two groups: (1) those who seek to demonstrate that a person really dies when a syndrome called brain death occurs, and

(2) those who consider that a person in a state of so-called brain death, even if alive, can be treated as a donor of organs for transplantation because of the greater good that is achieved through this.

The (1) group includes defenders of the theory of brain death on the Catholic side. They believe that this theory has a sufficiently strong scientific basis for it to be considered valid. And the (2) group includes all those who recognise the utilitarian principle that says that an act is good if the sum of the good in the world is the result of this act increased. Since it is believed that people in a state of so-called brain death have no chance of survival, it is also believed that their death can be accelerated for the good of others. In fact, it is consent for the killing of a living, innocent person.

If, however, people in a state of so-called brain death are living, as shown by the arguments above, it is indisputable that the Catholic Church cannot accept the treatment of these people as donors of organs for transplantation. After all, the act of depriving each such person of his or her life is something worse, from a moral point of view, than euthanasia. Euthanasia, as we know, is justified by the good of the suffering person, who in this way is freed from suffering, and in the case of killing a person who lives in order to remove his organs for transplantation, there can be no talk of any good for that person resulting from such action.

\section{Summary}

In this article I first tried to demonstrate that the theory of so-called brain death is unsustainable from a scientific point of view. The data that the medical profession provides on this subject clearly contradicts such a theory. It is impossible to prove, on the basis of the knowledge available to this science that people who are in a state of cerebral death are really dead. The only thing that the doctor can say, without exceeding the limits of the discipline he represents, is that these people have a significant degree of brain damage. This does not mean, however, that the brain is so damaged that is has ceased to perform all 
its functions. On the contrary, these patients usually show many symptoms of brain activity. Recognition of these sick people as dead, therefore, contradicts the principles of the medical art.

The acceptance of the theory of so-called brain death has also given rise to many problems from the legal point of view. Recognition as a living or deceased person depends on the criteria for brain death, which vary from country to country. The law has therefore become arbitrary in such an important area as human life and death.

The adoption of the theory of brain death on the basis of such un-robust scientific criteria has undoubtedly become possible only through the acceptance of certain philosophical assumptions that reduce the human to his or her consciousness. A permanent loss of consciousness was de facto considered to be evidence of human death. This position contradicts the achievements of Christian thought in the field of philosophical anthropology, which emphasises the unity of the individual and the importance of his or her bodily aspect. What is even more important, however, is the fact that modern man tends to think in terms of moral utilitarianism. Many people believe that it is possible to sacrifice the life of a person who is seriously ill and who has no hope of improvement (in this case, a person with cerebral death syndrome) for the benefit of other patients. This attitude explains the passivity of many circles and the failure to discuss such an important issue as the rightness or wrongness of the theory of so-called brain death. It is not without significance that there is a specific transplant lobby in individual countries, which puts moral pressure on entire societies to accept the removal of organs for transplantation from people who are in a state of so-called brain death, and suppresses the discussion of moral problems associated with it.

It is necessary for the Catholic Church to develop a clear position on this matter. This has not yet happened. There is even a surprising lack of consensus among various the authorities. However, some of the hierarchy of the Catholic Church have already spoken on this matter. These include Cardinal Meissner, Archbishop of Cologne, who clearly rejected the theory of brain death as incompatible with the principles of the Church's teaching ${ }^{21}$. Pope John Paul II also wrote in the encyclical Evangelium Vitae: "Nor can we remain silent about the existence of other, better camouflaged but no less dangerous forms of euthanasia. We would be dealing with them, for example, if, in order to obtain more 
organs for transplantation, we proceeded to collect these organs from donors before they were declared dead according to objective and adequate criteria."

Although these words do not mention the concept of brain death, they refer to it indirectly. This paper was written in order to draw attention to just such a moral problem hidden in the concept of so-called brain death.

In conclusion, I would like to give the floor to one of the participants in the discussion on brain death, Dr Tomoko Abe. She wrote: "It is true that the latest developments in science and technology have brought many benefits. At the same time, however, they have brought unprecedented confusion in philosophy and culture to our societies. Due to the destructive tendencies of the present day, it is becoming increasingly important to establish social standards to protect the most vulnerable members of society, such as young children and unconscious patients who cannot defend themselves. We therefore conclude that the current diagnostic criteria for brain death should be abolished and that a worldwide ban on transplants from people with cerebral death syndrome should be introduced." 22

Dr. Abe is not alone in a desire to overthrow the theory of so-called brain death and to consider its criteria as non-scientific. The same is demanded by many other authors. The voice of the Catholic Church in this matter is undoubtedly one of the most important. As the greatest authority in the world in matters of morality and human rights, it cannot fail to explain the issue of so-called brain death in its teaching. 